\title{
NOTAS
}

\section{Lectura del "Himno a la Luna" de Lugones*}

I

Es preciso establecer distinciones en la compleja maraña del asî llamado Modernismo en Hispanoamérica. Creo que todos somos muy conscientes de su riqueza y variedad, como de las encontradas metas que gobiernan los intentos de los poetas que lo componen. Hay una lïnea creadora, casi constante, que ya se insinúa en un José Asunción Silva poco frecuentado, en cierto Herrera y Reissig, y que alcanza su culminación en el Lunario sentimental. Las fuentes de tal actitud hay que buscarlas no en las tardǐas formas parnasianas o simbolistas que se hacen presentes en el Primer Modernismo, sino en las coloquiales displicencias del asîl llamado décadentisme. El viejo símbolo, la vieja metáfora, aquí sólo se presta para exaltar lo que el poeta ve como el esqueleto de un sueño, el espectro de una ilusión aún no del todo desaparecida. La exaltación celebratoria se ha transformado en una mueca que si no trasunta dolor, comunica al menos un sinsabor persistente. Ese mundo de pierrots, de payasos, nos señalan abiertamente la grotesca condición humana y nos introducen en un espacio poemático de oblicuidades, de discordancias, de notas dadas en falsete. La voz siempre trasunta segundas y clandestinas intenciones.

En Silva este tipo de poesǐa es testimonio de un desdoblamiento espiritual del poeta. Así vemos que contrastan hasta la violencia poemas como "Ars" por un lado y "Zoospermos" por otro. En el primero hallamos los ingredientes del Modernismo establecido, un tanto seguro y hasta algo solemne. En el segundo, una variedad de niveles de expresión que lo sitúan fuera de esta corriente.

*Desearía que este ensayo se leyera como una nota adicional al importante trabajo de Alfredo Roggiano aparecido en la Revista Iberoamericana, No. 94, pp. 71-77: "Qué y Qué No del Lunario sentimental". 
Ars

El verso es un vaso santo; poned en él tan solo Un pensamiento puro,

En cuyo fondo bullan hirvientes las imágenes

Como burbujas de oro de un viejo vino oscuro.

Alli verted las flores que en la continua lucha

Ajó del mundo frío

Recuerdos deliciosos de tiempos que no vuelven,

Y nardos empapados en gotas de rocío.

Para que la existencia misera se embalsame

Cual de una ciencia ignota,

Quemándose en fuego del alma enternecida

De aquél supremo bálsamo, ¡baste una sola gota!

La noción de santidad, de ceremonia, está presente desde el primer verso $y$, naturalmente, la idea de lo puro. Tales esencias se acercan a las concreciones preciosas del oro y del vino añejo. Si la real existencia es mísera está al menos el sueño de la pureza y de lo bello, bálsamo que el poeta busca como un elixir alquîmico. Veamos el segundo poema:

Asǐ el ilustre sabio

Cornelius Van-Kenrinken,

Que disfrutó en Hamburgo

De una clientela enorme

Y que dejó un in-folio

De setecientas páginas

Sobre hígado y riñones,

Abandonado luego

Por todos sus amigos,

Murió en Leipzig maniático,

Desprestigiado y pobre,

Debido a sus estudios

De los últimos años

Sobre espermatozoides.

Sin duda aquǐ Silva ya está en el mundo irónico que Lugones desnudará de todo elemento emocional en su "Himno a la luna", por ejemplo. No sólo hay una irrupción del lenguaje de la calle, sino que aquí se han dejado las búsquedas de lo puro o lo bello. Los elixires y los bálsamos son sustituidos por la 'verdad' de la ciencia. Como la historia que se narra en el poema, el desencanto se trasunta en la forma 
expresiva que no admite embellecimiento. Hay que notar que esas referencias biológicas, son parte de otra versión del Amor, con mayúsculas, aquí reducido a su razón más elemental. Estamos, pues, a un paso de Laforgue.

Es posible entonces sugerir una línea creadora que en verdad es un tanto extraña a lo que en general entendemos por "Modernismo" en Hispanoamérica y que desde Silva se proyectarǐa al Lugones del Lunario y a cierto Herrera y Reissig. Sabemos que Lugones incluyó en el Lunario poemas escritos desde 1902, aproximadamente. Su "Himno a la luna" es ejemplar, en su exageración. Junta todos los defectos y las virtudes que hacen de esta poesía algo activo y evidentemente polémico.

\section{II}

Es necesario insistir que en los procesos mentales que determinan la metáfora o el sìmil lugoniano hay siempre una trabazón racional. A veces la comparación de los términos evidencia un laborioso y cuidado ensamblaje. No hay una búsqueda de lo bello, del ensueño, de la entrega intuitiva, sino de un sistema de relaciones que solamente hace posible la presencia de un elemento crítico que posee una aspereza tal como no la habiamos encontrado tal vez desde el Siglo XVII. Es una acidez, un acercamiento de la palabra que hiere y rompe cualquier visión idealizante. Es más, el idioma de Lugones en el Lunario nos enfrenta a una serie de disonancias, de obstáculos tanto semánticos cuanto fónicos, que altera nuestra disposición ante esos textos.

La luna, una vez deidad antigua, rodeada del prestigio de un pasado que la elevaba a sìmbolo de idealizaciones, aquî̉ entra en nuestro mundo moderno:

Para que alumbres sin mayores ironías,

$\mathrm{Al}$ poligloto elogio de las Guǐas,

Noches sentimentales de misses en Italia.

Pasar del esplendor mitológico a las guỉas de turismo es un acto de desacralización que el poeta cumple con manifiesta displicencia. Desde allí nos prepara para cualquier voltereta, para todas las combinaciones posibles. Las rosas, sîmbolos tantas veces de la pureza, aquǐ se embriagan de etileno, es decir de un producto industrial. Por eso escribe a continuación: 
Yo te hablaré de maneras corteses

Aunque sé que sólo eres un esqueleto.

En efecto, es una visión totalmente descarnada, deliberadamente libre de todo intento de embellecimiento y, en consecuencia, capaz de las comparaciones más sorprendentes. Borges ya señaló la originalidad y curiosidad de las rimas lugonianas. Ellas pueden introducirse al poema justamente por esa libertad crĭtica que el poeta declara para sí.

¡Cuánto, cuánto albayalde

Llevas gastado en balde

Para adornar a tu hermana morena!

"Albayalde" y "balde" nos ponen en un plano de parodia en el que todos los tonos son posibles. A veces es familiar y amistoso - "Te amo porque eres generosa y buena"- y otras de un afectado pulimiento que trasunta la burla: "Oh astronómica siempreviva!" Al alumbrar las blancas masas polares la luna pasa igual que "púdica monja que cuida un hospital." Todas las alusiones a la naturaleza tienen una irrealidad paródica que sugiere una intencionada artificialidad:

En las piscinas

Los sauces, con poéticos desmayos,

Echan sus anzuelos de seda negra a tus rayos

Convertidos en deslumbrantes sardinas.

Es éste un felicǐsimo momento en el poema. Esta estrofa que nos hace sonreĭr, no carece de encanto imaginativo. Los "poéticos desmayos" de los sauces sugieren una teatralidad excesiva, como si la naturaleza participara de una escenografía exagerada. Las ramas que tocan el agua se convierten en "anzuelos" que pescan los rayos aquî reducidos a prosaicas sardinas. Por eso en la estrofa siguiente nos aclara aún más su actitud:

Mi ojo científico y atento

Su pesimismo lleno de pericia.

Nada más apto para definirse. Su observación es siempre objetiva, penetrante, "cientǐfica". Y en su implǐcito pesimismo -ya que se opone al sueño romántico- hay una innegable capacidad de detalle, una búsqueda que requiere habilidad, "pericia" desusual. Lugones logra una activa combinación al unir una noción como el pesimismo con la noción de pericia. Es decir una cualidad espiritual con una pa- 
labra que siempre asociamos con una técnica. Tal tipo de recurso se utiliza en el poema una y otra vez. Por ejemplo, "satina morbideces de cold-cream y de histeria." Aquí el contraste está todavĭa más acentuado por la presencia del neologismo inglés, sólo incorporado en nuestro idioma en la jerga de la publicidad de cosméticos. Además, tal lenguaje en un himno, violenta aún más nuestras aceptadas nociones de propiedad.

$\mathrm{Y}$ asì la luna, un dỉa deidad reverenciada, aquî ha quedado reducida a una humilde función: "Hada de las lentejuelas". En su viaje por el espacio a veces parece un témpano que cruzara nubes, pero estas nubes son "al bromuro". Al galicismo de menú hay que agregar la presencia de la química industrial $\mathrm{y}$, sin embargo, el bromuro sugiere también el narcótico, el sueño irreal y casi diríamos "moderno" por excelencia, ya que necesita del sedante. La trabazón racional que ordena las comparaciones siempre tiene una viva actividad, con reverberaciones semánticas, con asociaciones varias que operan simultáneamente en varios planos. Siempre el adjetivo afilado, la visión penetrante y descreida modifican actitudes convencionales. El detalle fotográfico, la aprehensión de un cuadro en toda su concreción, nos revela con insistencia ese tono de ambigüedad, de oblicuidad que es esencia misma de la parodia.

Lugones, que parece cumplir una función de dinamitero, entrega, en realidad, nuevos instrumentos al verso en español y abre nuevas áreas de poetización. Sus disonancias nos sacan de nuestras complacientes actitudes, nos irritan, nos aperplejan. Atacan y abruman con sus riquezas intencionadamente librescas y con su erudición de enciclopedia. Esa reventazón de vocablos, ese regreso al diccionario que el poema parece proponer, nos invita a otra forma de lectura y a un placer de orden nuevo. Asĩ escribe:

El transeúnte que taconea un caso

Quirúrgico, en la acera obscura,

Trabucando el nombre poco usual

De un hemostático puerperal.

Este humor negro aún se hace más brutal cuando pensamos que es una parturienta la que ha lanzado a la calle a ese transeúnte. En idéntica vena quevediana nos habla también de "el ahorcado que templa en do, re, mi, su soga". La luna alumbra mucho dolor y sufrimiento, pero el tono es aquî̉ de comedia ligera, de burla que lo rebuscado del lenguaje menos esconde que destaca. 
Cada estrofa, de metro variado y libre, es una viñeta reveladora de gestos, situaciones, momentos invariablemente paródicos:

Entre álamos que imitan con rectitud extraña,

Enjutos ujieres,

Como un ojo sin iris tras de anormal pestaña,

La luna evoca nuevos seres.

O bien la estrofa siguiente:

Mayando una melopea insana

Con ayes de parto y de gresca,

Gatos a la valeriana

Deslizan por mi barbacana

El suspicaz silencio de sus patas de yesca.

$Y$ es que ese ojo sin iris penetra en todos los rincones, alumbra los objetos más variados y da al poeta la libertad de una estructura impuesta más por la imaginación que por el acontecer en el poema. Ese ojo es asimismo el ojo del poeta que no acepta, ni por un momento, marcos de significación preestablecidos. No hay separación posible en su visión entre lo bello, lo prestigioso por un lado y lo modesto, lo común y cotidiano por otro. "Patas de yesca" es un hallazgo feliz. En verdad, todos los animales a que alude Lugones en el poema están pintados con ánimo caricaturesco. El murciélago parece "un negro plumerillo que limpia una vidriera." El "can lunófilo" como "una damisela llora enterneciendo a los serafines". El tiburón es "voraz como un lord en Irlanda". El león "diseña con gesto merovingio su cara grandiosa". "El ruiseñor. . . con lírico delirio filosofa". El tigre tiene una "mirada hipócrita como una ganzúa". El buho posee ojos "de caldo". Los lobos, "agudos rostros judiciales". Los chacales viven en su "democracia". La hiena es "oblicua". Las cigarras "crepitan". Los grillos frotan "agrios esmeriles". Es que los animales con parte de esa naturaleza que el poeta ve como algo risueñamente excesivo, con una irrealidad de utilerĭa.

Lo mismo es aplicable al hombre cuando aparece en el poema. $\mathrm{El}$ amor de esa joven que la noche termina venciendo y que vive su palpitación erótica “... ahoga su ay soprano un gallo del distante cortijo". Y antes habíamos visto aquel transeúnte que en desesperación buscaba algo para contener la hemorragia de su mujer.

Hacia el final del poema hay una estrofa que hubiera podido salir de la pluma de Jarry y que anticipa muchos de los experimentos poéticos futuristas y luego dadaístas: 


\author{
El residuo alcalino \\ De tu aire, en que un cometa \\ Entró como un fósforo en una probeta \\ De alcohol superfino; \\ Carámbanos de azogue en absurdo aplomo; \\ Vidrios sempiternos, llagas de bromo; \\ Silencio inexpugnable; \\ Y como paradójica dendrita. \\ La huella de un prehistórico selenita \\ En un puñado de yeso estable.
}

Palabras como "alcalino", "probeta", "alcohol", "bromo", "dendrita" no habían antes llegado a nuestra poesía. Es a Lugones a quien corresponde el mérito de habernos ganado estos nuevos territorios. Las novedades de Marinetti, de Apollinaire, resultan menos sorprendentes si se piensa que el Lunario sentimental se publicó en 1909, como recopilación de textos ya aparecidos antes! En comparación con el "Himno a la luna" los otros poemas del Lunario son menos arriesgados. Tal vez por ello mismo, son composiciones a menudo más perfectas, más acabadas.

El "Himno a la luna" vale por su desmesura, por su impertinente exageración como por esa libertad desafiante e irreverente. Tal vez algo que aterró al mismo Lugones. Ya sus Odas seculares de 1910 indican un retorno a la mesura y a una poesia casi "oficial". El Lunario es un experimento crucial en nuestra poesía y aún podría decirse, si nos atenemos a una proyección temporal, de la poesía de Occidente. La insularidad europea es tan injustificable como la nuestra. Estos textos de Lugones, vistos en tal perspectiva, poseen, más allá de su condición meramente innovadora, algo que los torna proféticos. 
